\title{
VARIACIÓN FONÉTICO-FONOLÓGICA DEL MAPUDUNGUN HABLADO POR NIÑOS BILINGÜES DEL ALTO BÍO-BÍO: EL CASO DE LOS FONEMAS FRICATIVOS /ð/ Y /v/
}

\section{PHONETIC-PHONOLOGICAL VARIATION IN THE MAPUDUNGUN SPOKEN BY BILINGUAL CHILDREN FROM ALTO BÍO-BÍO: THE CASE OF FRICATIVE /ð/ AND /V/ PHONEMES}

\author{
Fernanda Narváez Fuentes \\ Universidad Católica de la Santísima Concepción \\ fnarvaez@magister.ucsc.cl \\ Marisol Henríquez Barahona \\ Universidad Católica de la Santísima Concepción \\ mhenriquez@ucsc.cl
}

\section{Resumen:}

En este artículo se presentan los principales rasgos de variación fonético-fonológica de los fonemas fricativos $/ ð / \mathrm{y} / \mathrm{v} /$ del mapudungun hablado por niños del Alto Bío-Bío. Los colaboradores fueron 25 escolares bilingües, pertenecientes a comunidades del valle del Queuco y del valle del Bío-Bío, cuyas edades fluctúan entre los 10 y 14 años. Según los datos analizados, estos hablantes presentan diversos rasgos de variación o innovaciones fonético-fonológicas asociadas a los fonemas en estudio, que se pueden atribuir fundamentalmente al contacto sociolingüístico. Sin embargo, el grado de difusión de estos rasgos no ocurre de forma homogénea entre los hablantes, ni entre las comunidades.

Palabras clave: mapudungun - niños bilingües - fonología - variación por contacto - Alto Bío-Bío.

\begin{abstract}
:
This paper presents the main phonetic-phonological variation features of the fricative $/ \delta / y$ /v/ of Mapudungun spoken by children from Alto Bío Bío. The participants were 25 bilingual schoolchildren, from communities of the Queuco Valley and Bío Bío Valley, whose age fluctuates between 10 and 14 years old. According to the examined data, the speech of these speakers presents several variation features associated with the phonemes under study. This can be attributed primarily to sociolinguistic contact. Nevertheless, the diffusion degree of these features does not occur homogeneously among the speakers nor among the communities.
\end{abstract}

Key words: mapudungun - bilingual children - phonology - variation for contact - Alto Bío - Bío.

Recibido: 16 de enero de 2020

Aceptado: 10 de noviembre de 2020 
Artículo. Fernanda Narváez Fuentes, Marisol Henríquez Barahona. "Variación fonético-fonológica del mapudungun hablado por niños bilingües del Alto Bío-Bío: el caso de los fonemas fricativos $/ \mathrm{d} / \mathrm{y} / \mathrm{v} /$ "

\section{Introducción}

La coexistencia de sociedades y de lenguas tiene como consecuencia múltiples fenómenos sociales y lingüísticos, ya que, los sistemas que están en contacto se alteran o modifican mutuamente en todos los niveles: en el plano morfosintáctico, léxico-semántico, pragmático y fonológico (Silva-Corvalán y Arias, 2017; Moreno-Fernández, 2009; Palacios, 2011; Blas Arroyo, 2012). Cuando se trata de un contacto histórico, intenso y asimétrico se incrementan las influencias; especialmente de la lengua socialmente dominante sobre la minoritaria, lo que incluso podría desencadenar un proceso de desplazamiento lingüístico (Thomason, 2001; Areiza, Cisneros y Tabares, 2011). Tal pareciera ser el caso del contacto castellano-mapudungun, en el que la lengua originaria ha evidenciado en los últimos tiempos un notorio proceso de retracción funcional, que se manifiesta de manera más extrema en el segmento generacional de los niños y jóvenes mapuche (Alonqueo, Wittig y Huenchunao, 2017; Wittig y Alonqueo, 2018). En este contexto, de contacto histórico entre sociedades y lenguas, se ha documentado la posibilidad de observar variación estructural, principalmente en los planos fonológicos y sintácticos de las lenguas en relación (Thomason y Kaufman, 1988).

En efecto, en el nivel fonético-fonológico y a consecuencia del contacto, se presentan fenómenos de variación y cambio lingüístico que se caracterizan por la incorporación de nuevos rasgos, desde la lengua mayoritaria hacia la lengua minoritaria; los que incluso podrían modificar la estructura de la lengua receptora (Silva-Corvalán 2001; Thomason, 2001; Moreno-Fernández, 2009; Serrano 2011). En el caso del contacto mapudungun-castellano, la lengua oficial ha dejado huellas en el sistema lingüístico del mapudungun, lo que se constata fundamentalmente en investigaciones realizadas con niños pewenches de Alto Bío-Bío, en las cuales se ha observado la presencia de rasgos de variación en el sistema fonético-fonológico (Henríquez y Salamanca, 2015). Esto es evidente especialmente al contrastar su sistema fonético-fonológico con el de los adultos de la zona (Sánchez, 1989; Salamanca, 1997). Sin embargo, estas descripciones, aun son insuficientes para lograr un panorama más acabado del estado de la lengua y especialmente de la fonología de contacto de este grupo etario; por lo que en este estudio nos hemos 
planteado avanzar en este sentido y caracterizar los principales rasgos de variación fonético-fonológica presentes en el habla de los niños, al contrastarla con la de los adultos. Concretamente, se seleccionaron 2 segmentos consonánticos para el análisis; los fonemas fricativos /ð/ y /v/ del sistema fonológico de niños bilingües del valle del Queuco y del valle del Bío-Bío. Esta selección se explica en términos generales, por las siguientes razones:

a. Los fonemas $/ ð / \mathrm{y} / \mathrm{v} /$ han sido foco de controversias entre los especialistas que han descrito el sistema fonético-fonológico del mapudungun, especialmente en lo referido a la ausencia de las realizaciones áfonas de estos segmentos en el pewenche del Alto Bío-Bío, lo que argumentaría a favor de un distanciamiento de esta variante con el resto de los dialectos del mapudungun.

b. El fonema /ð/, junto a otros segmentos, ha sido considerado en la literatura como fonema crítico, ya que no se encuentra en el sistema fonológico del castellano, siendo exclusivo del mapudungun (Croese, 1980; Henríquez, 2017; Mena y Salamanca, 2018). En ese sentido, su estudio se torna muy relevante pues la presencia o ausencia de rasgos de variación por contacto entrega insumos sobre su permanencia y estabilidad en el sistema fonológico de los niños.

c. Finalmente, y considerando los puntos anteriores, el análisis de estos fonemas podría aportar de manera relevante a la discusión sobre la vitalidad y la adscripción dialectal del chedungun de Alto Bío-Bío.

En resumen, el análisis y descripción de estos segmentos permitirá conocer si el mapudungun de los niños presenta similitudes o diferencias con respecto a las descripciones fonológicas de los adultos de la zona (Sánchez, 1989; Salamanca, 1997) y, a su vez, entregará información sobre posibles diferencias en las realizaciones en distintas comunidades. 
Artículo. Fernanda Narváez Fuentes, Marisol Henríquez Barahona. "Variación fonético-fonológica del mapudungun hablado por niños bilingües del Alto Bío-Bío: el caso de los fonemas fricativos $/ \mathrm{d} / \mathrm{y} / \mathrm{v} /$ "

\section{Descripción fonético-fonológica de los fonemas fricativos /ð/ y /v/ del mapudungun.}

\subsection{Fonemas fricativos $/ \mathbf{d} / \mathbf{y} / \mathbf{v} /$}

Las descripciones fonético-fonológicos de los fonemas / / $/ \mathrm{y} / \mathrm{v} /$ del mapudungun hablado por adultos varían principalmente de acuerdo a variables dialectales o territoriales. Echeverría (1964) en su "Descripción fonológica del mapuche actual” registra dos variantes para el fonema / $/$ /: una realización áfona $[\theta]$ y otra sonora [ð]. Para el caso del fonema /f/ describe los alófonos: [f] fricativo labiodental áfono, $[\mathrm{v}]$ fricativo labiodental sonoro y $[\phi]$ fricativo bilabial áfono. Años más tarde, Salas (1978) coincide con Echeverría en la descripción de estos fonemas en su estudio del mapuche central. Plantea que el fonema fricativo interdental áfono $/ \theta /$, presenta los alófonos $[\theta]$ у [ð] en variación libre, con predominio del alófono sordo. Igualmente, reconoce la existencia de tres alófonos en variación libre para /f/: [f] fricativo labiodental sordo; [v] fricativo labiodental sonoro y [ $\phi]$ fricativo bilabial sordo, con una marcada preferencia por el alófono labiodental sordo.

Posteriormente, Lagos (1981), en su descripción de la fonología del mapuche hablado en las provincias de Malleco y Cautín de la novena región, puntualiza que el fonema $/ \theta$ / presenta dos realizaciones determinadas geográficamente: una variante áfona $[\theta]$ que se realiza en el sur y una sonora [ð] que ocurre más al norte. Para el caso de /f/, registra tres alófonos, que al igual que $/ \theta /$ establecen diferencias diatópicas dentro de la lengua: $[\phi]$ bilabial fricativo sordo que ocurre en el centro sur del territorio; [v] labiodental fricativo sonoro que ocurre en el norte del territorio y [f] labiodental fricativo sordo de la zona más meridional.

El mapuche lafkenche hablado en Tirúa, región del Bío-Bío, es descrito por Salamanca y Quintrileo (2009), quienes plantean que los fonemas fricativos /ठ/ y /v/ son

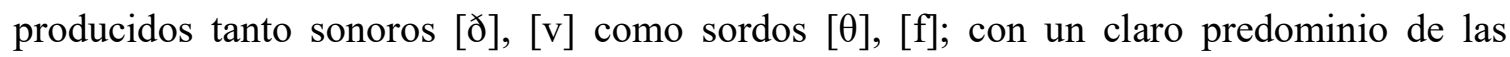
realizaciones sonoras. Más al sur, en la zona lafkenche de Isla Huapi, región de la Araucanía, Sadowsky, Painequeo, Salamanca y Avelino (2013) realizan un estudio en el que reconocen la existencia de los fonemas fricativos $/ \theta / \mathrm{y} / \mathrm{f} / \mathrm{los}$ cuales se realizan como 
sordos $[\theta]$ y [f], a diferencia del predominio de las sonoras [ð] y [v] del mapuche hablado en Tirúa.

Con respecto a la variante pewenche de Alto Bío-Bío, Sánchez (1989) plantea que el fonema /ð/ se realiza siempre como sonoro [ð]. Lo mismo para el caso de /v/ que presenta solo dos variantes sonoras $[\mathrm{v}],[\beta]$. Por su parte Salamanca (1997), quien describe también esta variante, coincide con Sánchez en la sonorización total de /ð/; sin embargo, para el caso del fonema $/ \mathrm{v} /$ distingue la ocurrencia de $[\mathrm{v}]$ y $[\beta]$, pero también reconoce la presencia de [f], destacando que este alófono "ocurre sólo en el postmargen silábico, en alternancia libre con $[\mathrm{v}]$ y con una frecuencia significativamente menor que el alófono sonoro" (p. 119).

En otro trabajo descriptivo desarrollado en la zona cordillerana de Lonquimay, Sánchez y Salamanca (2014) sostienen que los fonemas fricativos labiodental e interdental se realizan principalmente sonoros $[ð],[\mathrm{v}]$ y los alófonos áfonos $[\theta]$ y [f] se realizan con menor frecuencia y en posición de coda silábica. En el año 2016, Pérez y Salamanca analizan el sistema fonético-fonológico del mapuche hablado en Currarehue, donde el fonema fricativo interdental $/ \theta /$ presenta tres realizaciones alofónicas en variación libre: $[\theta]$ contoide fricativa plana interdental sorda, $[\chi]$ contoide fricativa plana interdental sonora y [s] contoide fricativa apicoalveolar sorda. El fonema/f/, por su parte, registra igualmente tres realizaciones alofónicas en variación libre: contoide fricativa plana labiodental sorda [f], contoide fricativa bilabial sorda $[\phi]$ y contoide fricativa plana labiodental sonora [v]. Los alófonos áfonos [ $\theta]$ y [f] son los que presentan mayor frecuencia en esta zona cordillerana.

Igualmente, en el año 2016, Mena desarrolló un estudio que se centró en las transferencias fonético-fonológicas en el pewenche de la zona de Alto Bío-Bío. En relación con los fonemas, foco de la presente investigación, señala que /ð/ presenta tres

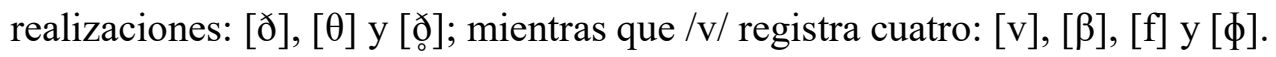

Con respecto al habla infantil, las primeras investigaciones fonético-fonológicas fueron realizadas con niños pewenches del Alto BíoBío. La descripción de Henríquez y Salamanca del año 2015, destaca, por ejemplo, que en las comunidades de Butalelbun y Caiñicu, el fonema /ð/ se realiza principalmente como alófono fricativo interdental sonoro [ð]; sin embargo, en la comunidad de Butalelbun se reportó con baja frecuencia la 
Artículo. Fernanda Narváez Fuentes, Marisol Henríquez Barahona. "Variación fonético-fonológica del mapudungun hablado por niños bilingües del Alto Bío-Bío: el caso de los fonemas fricativos $/ \mathrm{d} / \mathrm{y} / \mathrm{v} /{ }^{\prime}$

realización fricativa interdental áfona $[\theta]$. En Cauñicu, en cambio, la variante sorda $[\theta]$ no ocurre. En ambas comunidades, además, se observó el fono oclusivo [d], como variante de /ð/. En cuanto al fonema /v/, presentó en ambas comunidades los alófonos [v] y [f]. Asimismo, con muy baja frecuencia, en la comunidad de Butalelbun se registró el alófono fricativo bilabial sonoro $[\beta]$.

En otra descripción realizada con hablantes bilingües infantiles de 4 comunidades del valle del Queuco, Henríquez, ratifica que los fonemas fricativos labiodental sonoro /v/ e interdental sonoro /ð/ presentan realizaciones alofónicas sonoras $[v]$ y $[ð]$ y sordas $[\theta]$ y $[f]$, con un claro predominio de las primeras (2017).

En definitiva, se observa que las descripciones fonético-fonológicas de los fonemas /v/ y / / / del mapudungun de los niños coinciden en su mayoría con las descripciones tradicionales de los adultos de la zona, sin embargo, se aprecian algunas diferencias, especialmente en la incorporación de variantes emergentes, como la presencia del alófono $[\theta]$ y $[\mathrm{d}]$.

El presente estudio se propone, entonces, caracterizar los principales rasgos de variación presentes en los fonemas fricativos $/ ð / \mathrm{y} / \mathrm{v} /$ del sistema fonológico de niños bilingües del valle del Queuco y del valle del Bío-Bío. Para lograr este objetivo, se desarrolló una metodología de carácter descriptiva, en la cual se utilizaron dos herramientas de recolección de material fonético-fonológico y se realizó un análisis auditivo de las muestras de habla.

\section{La investigación}

Los datos fueron recolectados en el contexto del proyecto FONDECYT de Iniciación $\mathrm{N}^{\mathrm{o}} 11150508$, en cinco comunidades del valle del Queuco y del valle del BíoBío. En el valle del Queuco se consideraron las comunidades de Pitril, Trapa-Trapa y Butalelbun. En el valle del Bio-Bío se trabajó con hablantes de las comunidades de Ralco Lepoy y El Barco. 


\subsection{Los participantes}

Los participantes corresponden a un grupo de 25 niños pewenches, bilingües mapudungun-español, de entre 10 y 14 años. Estos colaboradores viven en alguna de las cinco comunidades seleccionadas. Cabe mencionar que todos ellos participaron de manera voluntaria y autorizada, para lo cual sus padres firmaron un consentimiento informado, mientras que los niños nos dieron su asentimiento informado.

\subsection{Estrategias para la recolección del material}

Para la elicitación del corpus fonético-fonológico se utilizaron dos estrategias: la aplicación de una lista léxica y la re-narración oral de un cuento breve en chedungun ${ }^{1}$.

La Lista léxica, estuvo compuesta por 100 palabras que se relacionan con partes del cuerpo, alimentos, términos de parentesco, flora, fauna, colores, numerales, etc. En ésta se incluyeron todos los fonemas de la lengua mapuche. Para su aplicación, el investigador le indicó a cada colaborador que repitiera en mapudungun en dos oportunidades la palabra que se le solicitaba en español.

Por su parte, la re-narración oral de una historia breve en chedungun contenía palabras seleccionadas de la lista léxica. Según el procedimiento, los hablantes escuchaban la grabación en dos oportunidades y posteriormente debían narrar la historia en mapudungun o contar lo que recordaban de ella. En los casos en que los niños tuvieron dificultad para narrar el cuento en mapudungun, o si en su relato no aparecían las palabras seleccionadas, se les realizaron algunas preguntas específicas sobre la historia para lograr la elicitación de las unidades léxicas.

\subsubsection{Sistema de Transcripción}

Las respuestas de los colaboradores fueron registradas en una grabadora TASCAM DR-40 y para un registro visual, se utilizó una cámara HANDYCAM SONY HDR-CX440.

\footnotetext{
${ }^{1}$ En este artículo utilizaremos los términos mapudungun y chedungun para referirnos a la lengua de los pewenches del Alto Bío-Bío; pues ellos utilizan ambas denominaciones para referirse a su lengua.
} 
Artículo. Fernanda Narváez Fuentes, Marisol Henríquez Barahona. "Variación fonético-fonológica del mapudungun hablado por niños bilingües del Alto Bío-Bío: el caso de los fonemas fricativos $/ \mathrm{d} / \mathrm{y} / \mathrm{v} /{ }^{\prime}$

La transcripción de las respuestas elicitadas se realizó con los símbolos del inventario fonético internacional (AFI), versión 2005, para lo cual se efectuaron audiciones pasivas y deliberadas de los datos registrados, los que posteriormente fueron revisados por expertos. Las transcripciones se registraron en una planilla Excel ad-hoc para su posterior análisis. En los casos dudosos, se realizó un análisis auditivo en el Programa Praat (Boersma y Weenink, 2019) por lo que fue necesario recortar frecuencias bajas (menores a $60 \mathrm{~Hz}$ ) y altas (mayores a 15000Hz) para evitar la influencia de algún ruido (Correa, 2014).

\section{Resultados}

\subsection{Consideraciones previas}

En el análisis de resultados se distingue entre variantes tradicionales y variantes emergentes. Las primeras son aquellas realizaciones de la lengua que han sido descritas para el sistema fonológico del mapudungun hablado por adultos. Las segundas, corresponden a todas aquellas realizaciones o variantes presentes en el habla de los niños, pero que no se han descrito como parte del habla de los adultos. Según Escobar y Wölck (2009), estas variantes emergentes corresponderían a fenómenos de variación o usos innovativos, atribuibles a la situación de contacto lingüístico. Para estos casos, se incluirán espectrogramas en la descripción de los resultados.

Asimismo, en los resultados se distingue entre una realización y un alófono, el primer término incluye toda manifestación fónica segmental que ocurre al elicitar una determinada palabra. El alófono, en cambio, se concibe como parte del sistema fonéticofonológico del vernáculo (Salamanca, Cifuentes y Figueroa, 2011).

\subsection{Fonema fricativo interdental sonoro /ð/}

\subsubsection{Descripción del fonema fricativo interdental sonoro/ð/ en el valle del Queuco}

Los hablantes de las tres comunidades del valle del Queuco registraron un total de 168 ocurrencias del fonema/ð/. Del análisis de estas, se constató la existencia de 5 
realizaciones del fonema: $[ð]$ fricativa interdental sonora; [ $\theta$ ] fricativa interdental áfona; [d] oclusiva postdental sonora; [.t] aproximante retrofleja áfona y [n] nasal alveolar sonora.

De acuerdo a las descripciones fonológicas del mapudungun hablado por adultos, las variantes del fonema /ð/ son los fonos [ð] y [ $\theta]$; ambas realizaciones están presentes en el corpus analizado, pero en desigual ocurrencia. El alófono fricativo interdental sonoro [ð] presentó un notorio predominio en las tres comunidades, con un total de 144 realizaciones (86\%), por lo que se identifica como la forma básica del fonema (Salamanca, Cifuentes y Figueroa, 2011). Se registró al inicio de sílaba: (1) [ða.'ne] "nido”; (2) [ðo.mo.'tfe]

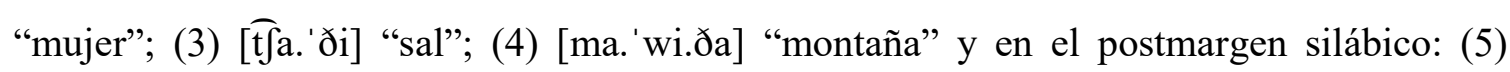
[tfoð] "amarillo". En cambio, el alófono áfono [ $\theta]$, sólo se constató en 2 ocasiones, en alternancia con [ð] en los ejemplos (1) y (5). En Pitril no se registró su ocurrencia.

Entre las variantes emergentes de /ð/, se registraron los fonos [d] , [n] y [^]. Al respecto, se puede señalar lo siguiente:

1. La realización oclusiva [d] ] se observó en las tres comunidades del valle, con un total de 8 realizaciones $(5 \%)$; todas se presentaron en posición inicial por sustitución fonológica, en palabras tales como: (6) [de.'jin] "volcán”, (2) [dro.mo.'t fe] “mujer". Para graficar este hallazgo presentamos (Figura 1) un espectrograma que evidencia esta ocurrencia.

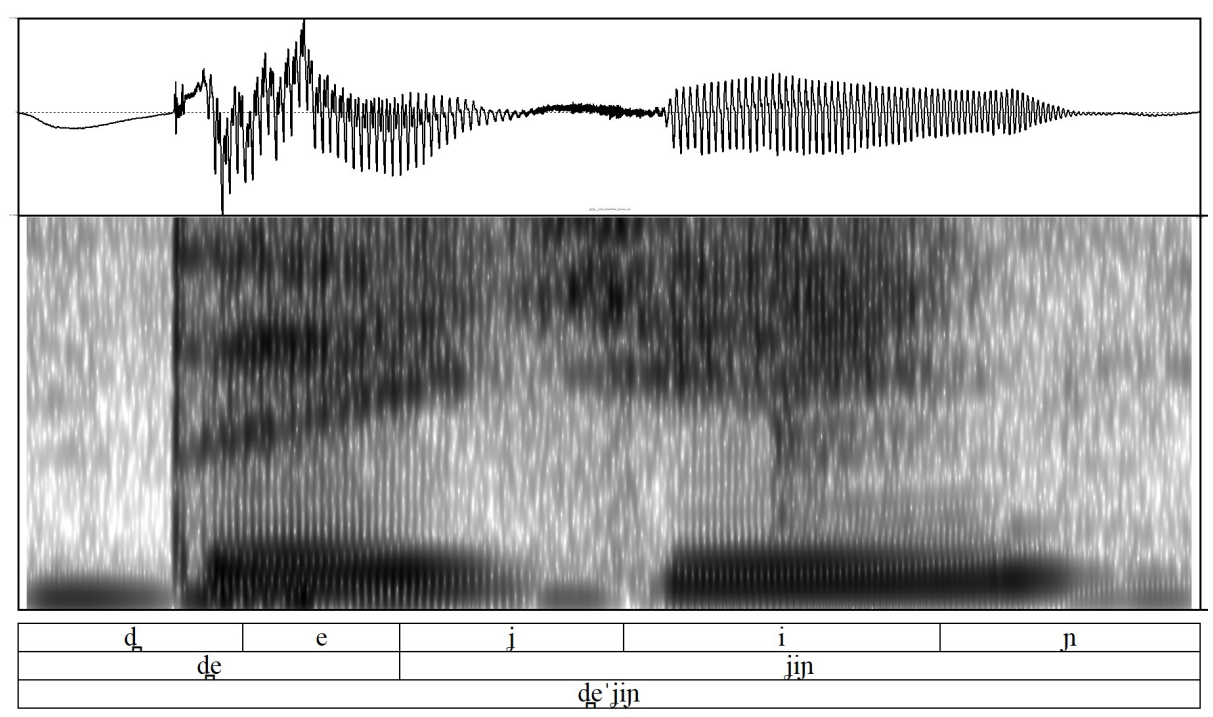

Figura 1. Espectrograma [de.'jij] 
Artículo. Fernanda Narváez Fuentes, Marisol Henríquez Barahona. "Variación fonético-fonológica del mapudungun hablado por niños bilingües del Alto Bío-Bío: el caso de los fonemas fricativos $/ \mathrm{d} / \mathrm{y} / \mathrm{v} /{ }^{\prime \prime}$

2. La realización nasal alveolar sonora [n], solo se observó en 2 ocasiones (1\%). Esta innovación (Figura 2) es una realización excepcional, pues la produce solo un hablante, por lo que no permite adelantar ninguna hipótesis sobre su estatus; no obstante, igualmente quisimos incorporarla. Se registró en la comunidad de Trapa Trapa por sustitución fonológica en (6) [ðe. 'jin] - [ne. 'jin] “volcán”.

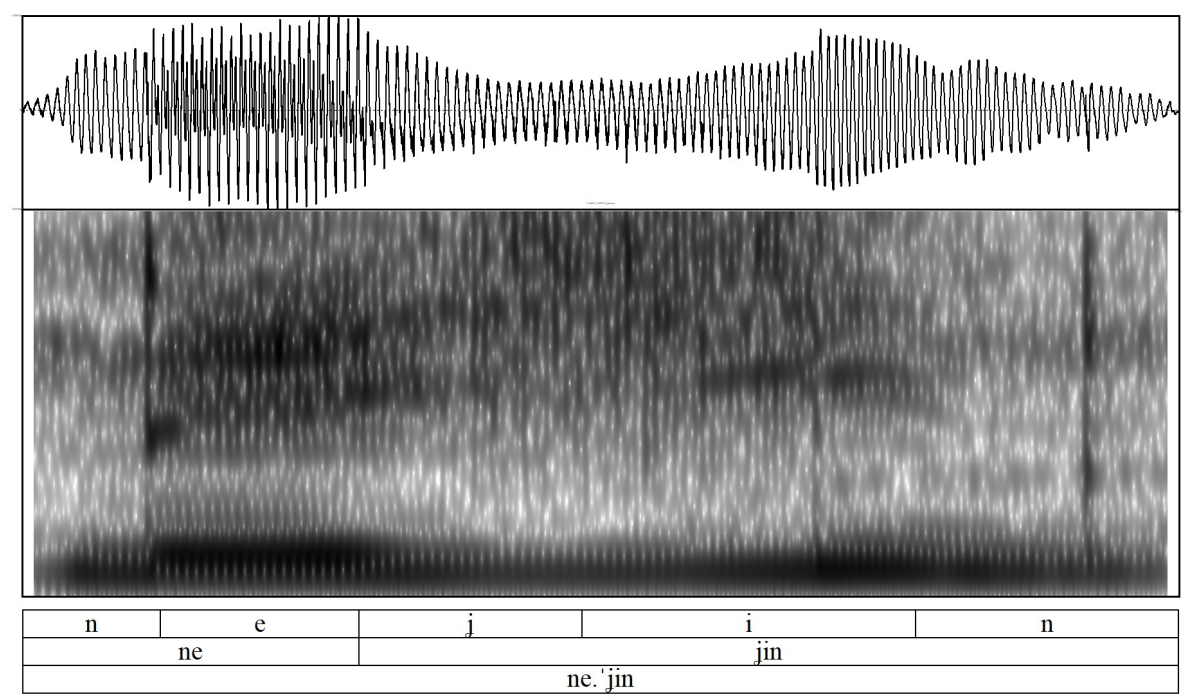

Figura 2. Espectrograma [ne. 'jin]

3. Finalmente, pudimos observar la presencia de un fono aproximante retroflejo [.] (Figura 3) en las comunidades de Butalelbun y Trapa Trapa con un total de 12 realizaciones, (7\%). Aparece solo en posición intervocálica al inicio silábico en el ítem (7) [we.'ða] "malo". Todos los escolares que respondieron esta palabra la realizaron compuesta y con presencia del fono [.t]: (8) [we.' ta. $\widehat{\text { f }}$ e]. 


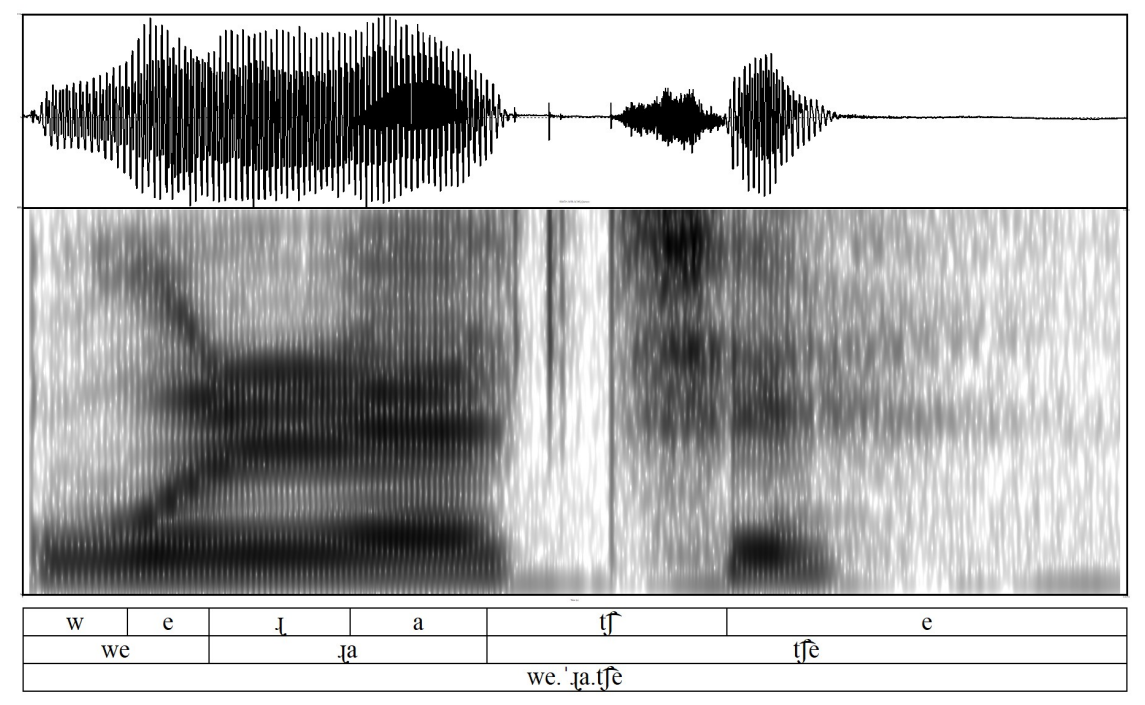

Figura 3. Espectrograma [we.' 'ta.t $\left.\int \mathrm{e}\right]$

La siguiente Tabla muestra el detalle de la realización de este segmento por comunidad:

Tabla 1. Realizaciones del segmento/ð/ en el valle del Queuco

\begin{tabular}{|c|c|c|c|c|c|c|c|c|c|c|c|c|}
\hline \multirow[b]{3}{*}{ comunidad } & \multicolumn{4}{|c|}{$\begin{array}{l}\text { realizaciones } \\
\text { tradicionales }\end{array}$} & \multicolumn{6}{|c|}{$\begin{array}{l}\text { realizaciones } \\
\text { emergentes }\end{array}$} & \multirow{2}{*}{\multicolumn{2}{|c|}{ Total }} \\
\hline & \multicolumn{2}{|c|}{ [ठ] } & \multicolumn{2}{|c|}{$[\theta]$} & \multicolumn{2}{|c|}{ [d] } & \multicolumn{2}{|c|}{ [.t] } & \multicolumn{2}{|c|}{$[\mathbf{n}]$} & & \\
\hline & $\mathrm{n}^{\circ}$ & $\%$ & $\mathrm{n}^{\circ}$ & $\%$ & $n^{\circ}$ & $\%$ & $\mathrm{n}^{\circ}$ & $\%$ & $\mathrm{n}^{\circ}$ & $\%$ & $\mathrm{n}^{\circ}$ & $\%$ \\
\hline Pitril & 19 & $86 \%$ & - & - & 3 & $14 \%$ & - & - & - & - & 22 & $100 \%$ \\
\hline Trapa Trapa & 61 & $87 \%$ & 1 & $1 \%$ & 2 & $3 \%$ & 6 & $9 \%$ & - & - & 70 & $100 \%$ \\
\hline Butalelbun & 64 & $84 \%$ & 1 & $1 \%$ & 3 & $4 \%$ & 6 & $8 \%$ & 2 & $3 \%$ & 76 & $100 \%$ \\
\hline Total & 144 & $86 \%$ & 2 & $1 \%$ & 8 & $5 \%$ & 12 & $7 \%$ & 2 & $1 \%$ & 168 & $100 \%$ \\
\hline
\end{tabular}

\subsubsection{Descripción del fonema fricativo interdental sonora /ð/ en el valle del Bío-Bío}

En el valle del Bío-Bío, el segmento /ð/ registró 92 ocurrencias. A diferencia de lo observado en el Queuco, se pudo constatar la existencia de solo dos variantes: [ð] fricativa interdental sonora y [d] oclusiva postdental sonora. No se observó la variante áfona [ $\theta]$. El detalle de estas realizaciones se presenta en la Tabla 2. 
Artículo. Fernanda Narváez Fuentes, Marisol Henríquez Barahona. "Variación fonético-fonológica del mapudungun hablado por niños bilingües del Alto Bío-Bío: el caso de los fonemas fricativos

Tabla 2. Realizaciones del segmento /ð/ en el valle del Bío-Bío

\begin{tabular}{|l|c|c|c|c|c|c|}
\hline \multirow{3}{*}{ Comunidad } & \multicolumn{2}{|c|}{ realización tradicional } & \multicolumn{2}{c|}{ realización emergente } & \multicolumn{2}{c|}{ Total } \\
\cline { 2 - 7 } & \multicolumn{2}{|c|}{$[$ [ð] } & \multicolumn{2}{c|}{ [d] } & \multicolumn{2}{c|}{} \\
\cline { 2 - 7 } & $\mathrm{n}^{\circ}$ & $\%$ & $\mathrm{n}^{\circ}$ & $\%$ & $\mathbf{n}^{\circ}$ & $\%$ \\
\hline El Barco & 18 & $69 \%$ & 8 & $31 \%$ & $\mathbf{2 6}$ & $\mathbf{1 8 \%}$ \\
\hline Ralco Lepoy & 57 & $86 \%$ & 9 & $14 \%$ & $\mathbf{6 6}$ & $\mathbf{7 2 \%}$ \\
\hline \multirow{2}{*}{ Total } & $\mathbf{7 5}$ & $\mathbf{8 2 \%}$ & $\mathbf{1 7}$ & $\mathbf{1 8 \%}$ & $\mathbf{9 2}$ & $\mathbf{1 0 0 \%}$ \\
\hline
\end{tabular}

La variante tradicional [ð] presentó 75 ocurrencias, equivalente al $82 \%$ del total de realizaciones del sector; por lo mismo la consideramos representante del fonema al igual que en el valle del Queuco. Este alófono ocurrió en variación libre al inicio de la sílaba (2), (4) y en el postmargen silábico (5). Por su parte, la variante emergente registrada en este valle, al igual que en el Queuco, fue la realización oclusiva [d] (Figura 4); aunque en estas comunidades, su ocurrencia es mayor, pues alcanza un 18\% de las realizaciones. Se presentó por sustitución fonológica en posición inicial, en ítems tales como (1), (2) y (6).

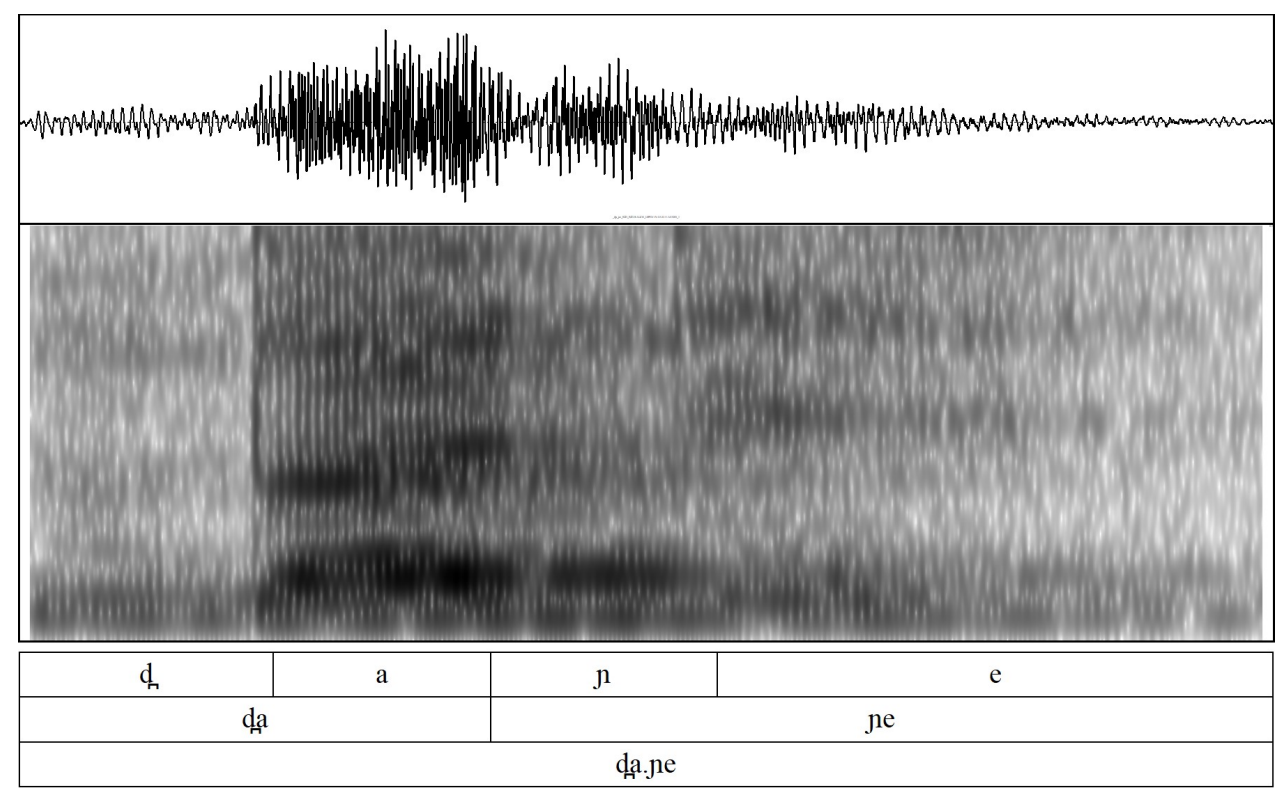

Figura 4. Espectrograma ['da.ne] 


\subsubsection{Análisis del fonema fricativo interdental sonora /ð/ en la zona de Alto Bío-Bío}

Al realizar un análisis de conjunto, se puede observar que en ambos valles predomina la variante [ð] del fonema /ð/. En efecto, del total de 260 realizaciones, 219 corresponden a la variante tradicional [ð] (84\%), mostrando un amplio predominio en las cinco comunidades estudiadas, lo que era teóricamente esperable. Dado su recurrencia y presencia en ambos valles, se identifica como la forma básica del fonema para la zona de Alto Bío-Bío.

El alófono [ $\theta]$ no se presenta en las primeras descripciones fonético-fonológicas de hablantes adultos de la zona (Sánchez, 1989; Salamanca, 1997). Según Salamanca (1997) “el fonema fricativo interdental /ð/ se realiza siempre sonoro en el pehuenche del Alto Bío Bío" (p.119); lo que significa que el fonema /ð/ siempre se realiza como [ð] y nunca como $[\theta]$. No obstante, en este estudio se registra el alófono [ $\theta]$ aunque con escasa presencia, lo que contraviene la hipótesis de la sonorización total. Esto es coincidente con lo descrito por Henríquez y Salamanca (2015) para el caso de niños, y con los hallazgos de Mena y Salamanca (2018) para los adultos de la zona; autores que describen la presencia de [ $\theta$ ] en el pewenche aunque con muy baja frecuencia. El alófono $[\theta]$ es característico del mapudungun central (Echeverría 1964; Salas 1976, Salas 1978; Lagos 1981; Salamanca, 2009; Sánchez y Salamanca, 2014; Pérez y Salamanca, 2016) no así del pewenche del Alto Bío-Bío, lo que podría justificar su baja frecuencia en el valle del Queuco e incluso su ausencia en el valle del Bío-Bío.

De todas las realizaciones emergentes, el fono oclusivo postdental sonoro [d] es el único que está presente en todas las comunidades del valle del Queuco y del valle del BíoBío, con un total de 25 realizaciones (9\%). Este alófono, no se había reportado para el pewenche de hablantes adultos (Sánchez, 1989; Salamanca, 1997); no obstante, se ha registrado en investigaciones más recientes de adultos pewenches (Mena, 2016; Mena y Salamanca, 2018) y también de niños (Henríquez y Salamanca, 2015), donde [d] se interpretó como una posible influencia del español y como un caso de desfonologización. En nuestros resultados se registra [d] , por lo que igualmente se hipotetiza que su ocurrencia sería un rasgo de variación fonética-fonológica producto del contacto lingüístico. 
Artículo. Fernanda Narváez Fuentes, Marisol Henríquez Barahona. "Variación fonético-fonológica del mapudungun hablado por niños bilingües del Alto Bío-Bío: el caso de los fonemas fricativos $/ \mathrm{d} / \mathrm{y} / \mathrm{v} /{ }^{\prime}$

En cuanto a la variante nasal alveolar sonora [n], como ya se señaló, solo un colaborador del valle del Queuco la realizo en una oportunidad por sustitución fonológica, por lo que no es posible considerarla alófono de /ð/.

Por último, llama la atención la sustitución de [ð] por el alófono aproximante retroflejo áfono [.]. Esto solo se observa en el valle del Queuco, en la comunidad de Butalelbun y Trapa Trapa, donde todos los colaboradores que respondieron el ítem "malo" [we.'ða] lo sustituyeron por [we. 'ta.ţe]. Este fono no ha sido descrito como alófono de /ð/. Sin embargo, es interesante consignar que en algunos diccionarios mapudungun-castellano, se usa [.] como variante de /ð/; como lo hace Moreno (2014) quien plantea que la acepción "el mal" en mapudungun se puede expresar de tres formas: [we.' ða] - [we.' 'ta] - [we.' ða .tfe]. En definitiva, su presencia en la zona es excepcional (5\%), con muy baja cobertura entre los niños, por lo que no se considera un alófono de /ð/. En el siguiente gráfico (Figura 5) se comparan las realizaciones del segmento.

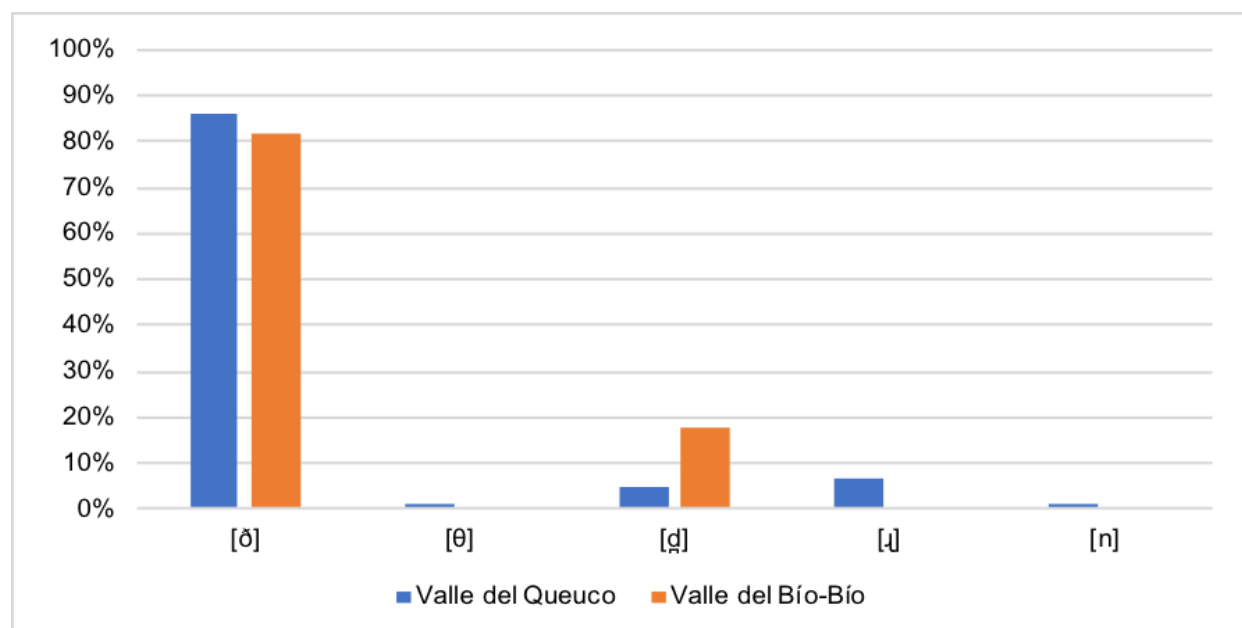

Figura 5. Comparación de realizaciones del segmento /ð/ entre los valles del Queuco y Bío-Bío

\subsection{Fonema fricativo labiodental sonoro /v/}

\subsubsection{Descripción del fonema fricativo labiodental sonoro /v/ en el valle del Queuco}

Para el segmento /v/ en este valle, se registraron 308 ocurrencias. Según el corpus analizado, se pudo constatar la existencia de cinco realizaciones de /v/: [v] fricativa 
labiodental sonora; [f] fricativa labiodental áfona; [ $\beta$ ] fricativa bilabial sonora; $[\mathrm{b}]$ oclusiva bilabial sonora y [p] oclusivo bilabial áfono. A continuación (Tabla 3), se presenta el detalle de estas realizaciones por comunidad.

Tabla 3. Realizaciones del segmento /v/ en el valle del Queuco

\begin{tabular}{|c|c|c|c|c|c|c|c|c|c|c|c|c|}
\hline \multirow[b]{3}{*}{ Comunidad } & \multicolumn{6}{|c|}{ realizaciones tradicionales } & \multicolumn{4}{|c|}{$\begin{array}{c}\text { realizaciones } \\
\text { emergentes }\end{array}$} & \multirow{2}{*}{\multicolumn{2}{|c|}{ Total }} \\
\hline & \multicolumn{2}{|c|}{ [v] } & \multicolumn{2}{|c|}{ [f] } & \multicolumn{2}{|c|}{$[\beta]$} & \multicolumn{2}{|c|}{ [p] } & \multicolumn{2}{|c|}{$[\mathbf{b}]$} & & \\
\hline & $\mathrm{n}^{\circ}$ & $\%$ & $\mathrm{n}^{\circ}$ & $\%$ & $\mathrm{n}^{\circ}$ & $\%$ & $\mathrm{n}^{\circ}$ & $\%$ & $n^{\circ}$ & $\%$ & $n^{\circ}$ & $\%$ \\
\hline Pitril & 48 & $59 \%$ & 7 & $9 \%$ & 6 & $7 \%$ & 8 & $10 \%$ & 12 & $15 \%$ & 81 & $26 \%$ \\
\hline Trapa Trapa & 72 & $69 \%$ & 18 & $17 \%$ & 3 & $3 \%$ & 10 & $9 \%$ & 2 & $2 \%$ & 105 & $34 \%$ \\
\hline Butalelbun & 93 & $76 \%$ & 19 & $16 \%$ & - & - & 10 & $8 \%$ & - & - & 122 & $40 \%$ \\
\hline Total & 213 & $69 \%$ & 44 & $14 \%$ & 9 & $3 \%$ & 28 & $9 \%$ & 14 & $5 \%$ & 308 & $100 \%$ \\
\hline
\end{tabular}

Como se puede observar, el fono fricativo labiodental sonoro [v] es por lejos el más recurrente, mostrando un evidente predominio sobre [f] y [ $\beta]$, con 213 realizaciones, lo que equivale al $69 \%$ del total; por lo que se identifica como la forma básica del fonema. Este alófono se presentó al inicio silábico (9) [mol. 'və̃] "sangre”, (10) [və. 'ta] "marido/viejo"; (11) [lew.'və] "río"; (12) [la.va.'ț̂a] "sapo"; (13) [vu.'ti] "espalda”; (14) [va.tfan.'tə] "hoy día” y en el postmargen silábico (15) [ku. '‘əv] "viento” y (16) [kov. 'kje] "pan”.

Por su parte, el fono [f] se registró en 44 ocasiones (14\%), en alternancia fonológica con [v]. Ocurre en posición silábica inicial (13) y en postmargen silábico (15), (16).

La tercera realización de /v/, es el fono fricativo bilabial sonoro [ $\beta]$, que produjeron 4 hablantes pertenecientes a las comunidades de Pitril y Trapa Trapa, en 9 ocasiones (3\%) y se presentó solo en el inicio de la sílaba por sustitución (9), (10) y por alternancia fonológica (11), (14).

Las variantes emergentes o innovaciones del fonema /v/ son: [b] y [p]. Sobre estas se puede señalar lo siguiente:

1. El fono oclusivo bilabial sonoro [b] (Figura 6) se observó en tres hablantes de la comunidad de Pitril y en dos de la comunidad de Trapa Trapa. Presentó un total de 14 
Artículo. Fernanda Narváez Fuentes, Marisol Henríquez Barahona. "Variación fonético-fonológica del mapudungun hablado por niños bilingües del Alto Bío-Bío: el caso de los fonemas fricativos $/ \mathrm{d} / \mathrm{y} / \mathrm{v} /{ }^{\prime \prime}$

realizaciones (5\%). Ocurre principalmente por sustitución y alternancia fonológica en el inicio silábico (13) y en el postmargen silábico (16).

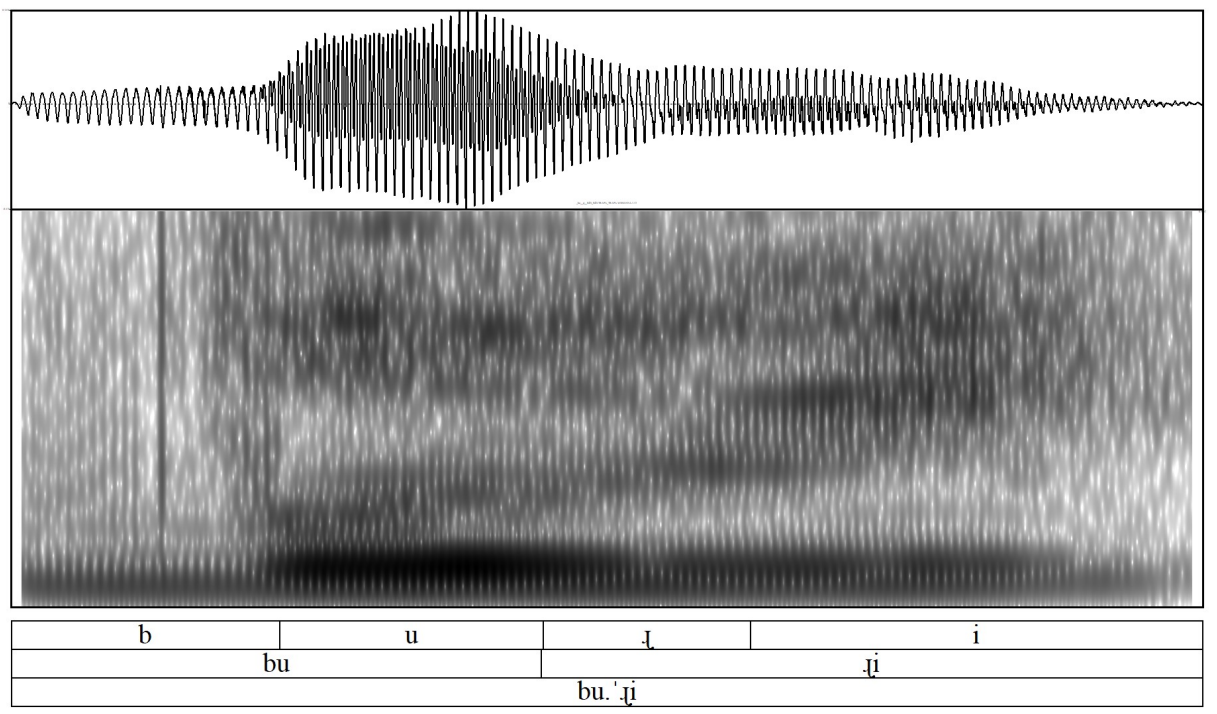

Figura 6. Espectrograma [bu.'ti]

2. Otra variante emergente es el fono oclusivo bilabial áfono [p] (Figura 7), que está presente en las tres comunidades del Queuco; cuatro niños de Pitril realizaron este fono, 3 niños de Trapa Trapa y 4 niños de Butalelbun, con un total de 28 realizaciones (9\%). Estas se presentaron por sustitución fonológica solo en el inicio silábico en los ítems (17) [pi.'țun] “humo” y (18) [рә.'ðo] “ombligo”. 


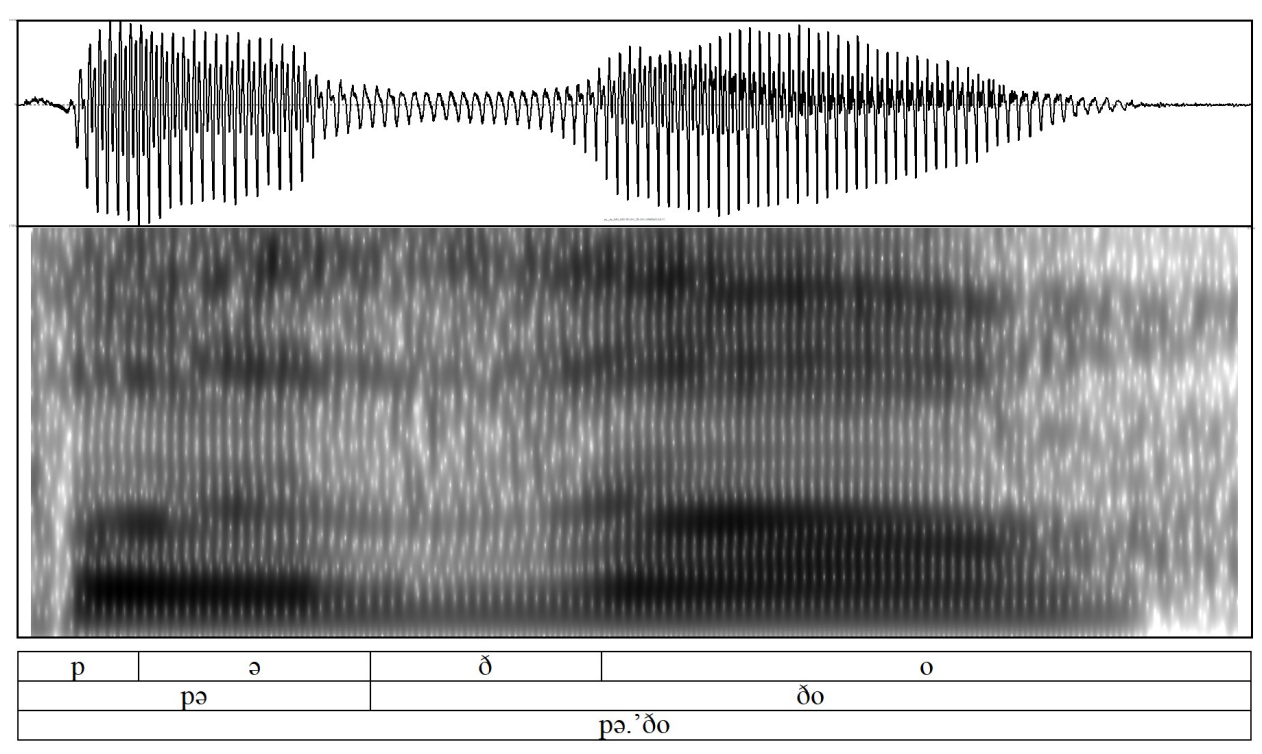

Figura 7. Espectrograma [рə.'ðо]

\subsubsection{Descripción del fonema fricativo labiodental sonoro /v/ en el valle del Bío-Bío}

En el valle del Bío-Bío, los colaboradores realizaron en 131 oportunidades el segmento /v/. Se observaron cinco realizaciones, las mismas registradas en las comunidades del valle del Queuco: [v] fricativo labiodental sonoro; [f] fricativo labiodental áfono; $[\beta]$ fricativo bilabial sonoro; $[\mathrm{b}]$ oclusivo bilabial sonoro y $[\mathrm{p}]$ oclusivo bilabial áfono. A continuación (Tabla 4), se presenta el detalle de las variantes del segmento /v/ en las comunidades del valle del Bío-Bío.

Tabla 4. Realizaciones del segmento /v/ en el valle del Bío-Bío

\begin{tabular}{|c|c|c|c|c|c|c|c|c|c|c|c|c|}
\hline \multirow{3}{*}{ Comunidad } & \multicolumn{6}{|c|}{ Realizaciones tradicionales } & \multicolumn{4}{|c|}{$\begin{array}{c}\text { Realizaciones } \\
\text { emergentes }\end{array}$} & \multirow{2}{*}{\multicolumn{2}{|c|}{ Total }} \\
\hline & \multicolumn{2}{|c|}{$[\mathbf{v}]$} & \multicolumn{2}{|c|}{$[\mathbf{f}]$} & \multicolumn{2}{|c|}{$[\beta]$} & \multicolumn{2}{|c|}{ [p] } & \multicolumn{2}{|c|}{ [b] } & & \\
\hline & $\mathrm{n}^{\circ}$ & $\%$ & $\mathrm{n}^{\circ}$ & $\%$ & $\mathrm{n}^{\circ}$ & $\%$ & $\mathrm{n}^{\circ}$ & $\%$ & $\mathrm{n}^{\circ}$ & $\%$ & $n^{\circ}$ & $\%$ \\
\hline Ralco Lepoy & 63 & $66 \%$ & 16 & $17 \%$ & 6 & $6 \%$ & 4 & $4 \%$ & 7 & $7 \%$ & 96 & $73 \%$ \\
\hline El Barco & 23 & $66 \%$ & 8 & $23 \%$ & -- & -- & -- & -- & 4 & $11 \%$ & 35 & $27 \%$ \\
\hline Total & 86 & $66 \%$ & 24 & $18 \%$ & 6 & $5 \%$ & 4 & $3 \%$ & 11 & $8 \%$ & 131 & $100 \%$ \\
\hline
\end{tabular}


Artículo. Fernanda Narváez Fuentes, Marisol Henríquez Barahona. "Variación fonético-fonológica del mapudungun hablado por niños bilingües del Alto Bío-Bío: el caso de los fonemas fricativos $/ \mathrm{d} / \mathrm{y} / \mathrm{v} /{ }^{\prime}$

Al igual que en el valle del Queuco, la variante tradicional [v] registró el mayor número de ocurrencias, con 86 realizaciones $(66 \%)$. Este alófono se presenta al inicio silábico (10), (14) y en el postmargen silábico (15), (16).

Por su parte, el alófono fricativo labiodental áfono [f], ocurre en menor medida que [v], registrando 24 realizaciones (18\%). Se presenta en alternancia y sustitución fonológica con [v], en el postmargen silábico (15), (16).

La tercera variante tradicional del fonema $/ \mathrm{v} /$, es el alófono fricativo bilabial sonoro $[\beta]$, el cual fue realizado por dos colaboradores en 6 oportunidades (5\%) y solo se observó en la comunidad de Ralco Lepoy, por sustitución fonológica (9), (11).

Entre las variantes emergentes del fonema /v/, se constataron igualmente, los fonos [b] y $[\mathrm{p}]$.

1. La realización oclusiva [b] (Figura 8), presentó 11 ocurrencias $(8 \%)$, superando el 5\%, registrado en el Queuco. Estas ocurrencias se presentaron por sustitución fonológica en el inicio silábico (10), (13), (14) y en el postmargen silábico (16).

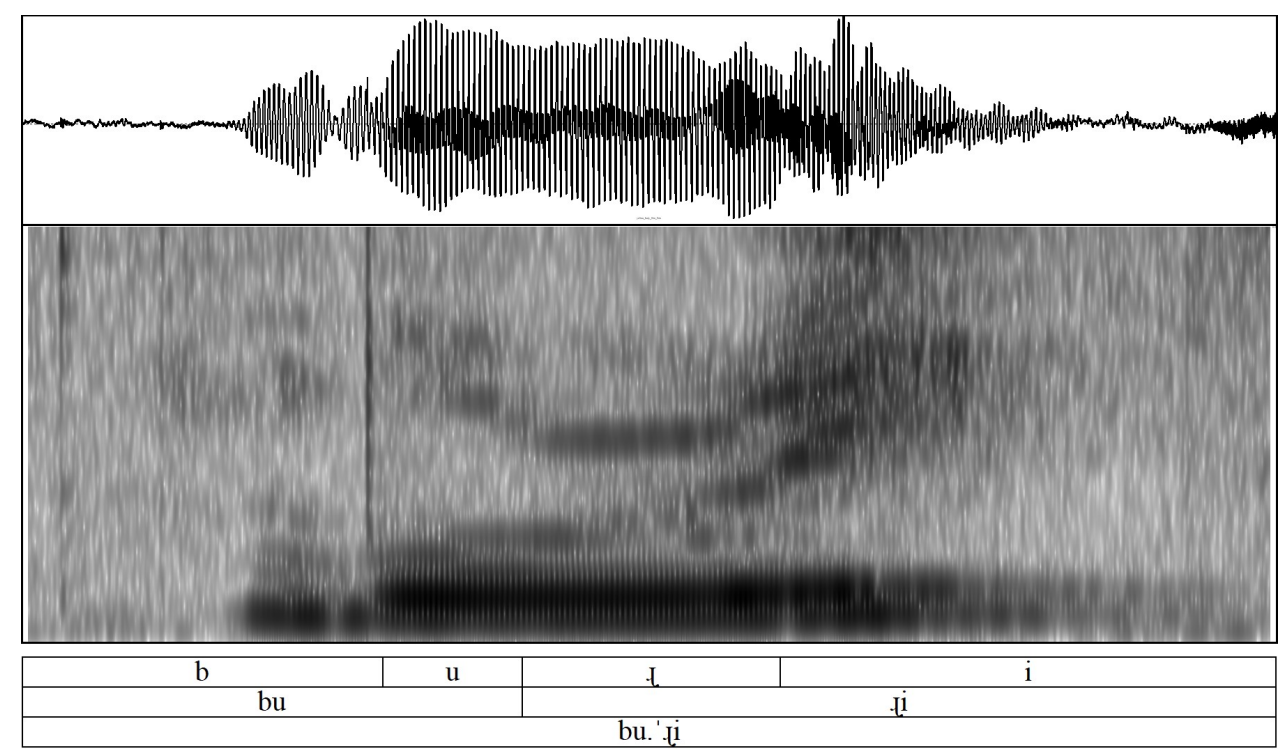

Figura 8. Espectrograma [bu.'ti] 
2. El fono oclusivo bilabial áfono [p] (Figura 9), solo ocurre en la comunidad de Ralco Lepoy y lo realizan dos colaboradores en 4 oportunidades (3\%). Se presentó por sustitución fonológica en el inicio silábico solo en la palabra (18) [pə.'ðo] “ombligo”.

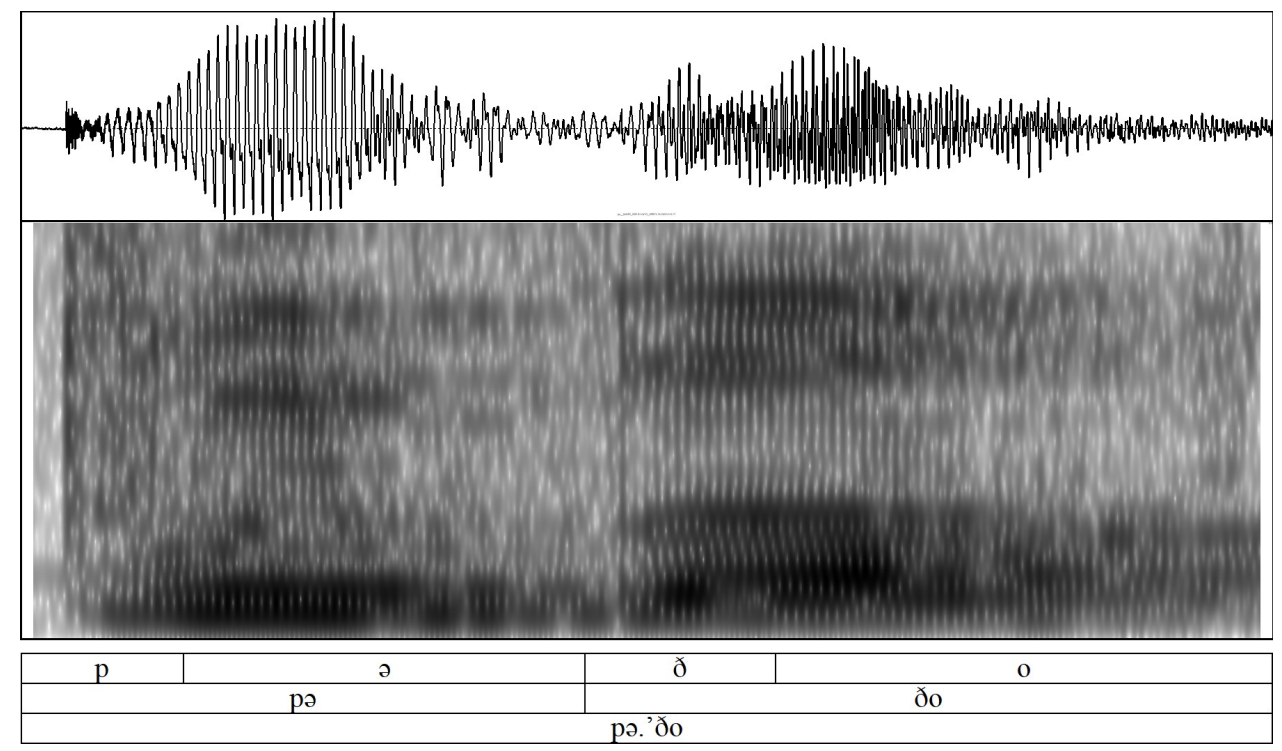

Figura 9. Espectrograma [рә.'ðо]

\subsubsection{Análisis del fonema fricativo labiodental sonoro /v/ en la zona de Alto Bío-Bío}

En la zona de Alto Bío-Bío predomina la variante [v] del fonema /v/; es decir, es la de mayor uso entre los niños de todas las comunidades, con 299 ocurrencias (68\%). Por su frecuencia y presencia en toda la zona, la hemos relevado como forma característica del fonema.

El alófono fricativo labiodental áfono [f], registra un total de 68 realizaciones en la zona, lo que representa el 16\% de las ocurrencias. Como se señaló, en la descripción de este alófono, la literatura ha documentado discrepancias: para el caso de los adultos, Sánchez (1989) describió que la fricativa labiodental se realiza siempre como sonora [v] y nunca como sorda [f]. No obstante Salamanca (1997), reconoce la existencia de [f] y menciona que "ocurre sólo en el postmargen silábico, en alternancia libre con [v] y con una frecuencia significativamente menor que el alófono sonoro" (p. 119). Para el caso del habla infantil, Henríquez, registra la ocurrencia del alófono [f] principalmente en el postmargen 
Artículo. Fernanda Narváez Fuentes, Marisol Henríquez Barahona. "Variación fonético-fonológica del mapudungun hablado por niños bilingües del Alto Bío-Bío: el caso de los fonemas fricativos $/ \mathrm{d} / \mathrm{y} / \mathrm{v} /{ }^{\prime}$

silábico, pero también en el inicio silábico, especialmente en niños pertenecientes a las comunidades del valle del Queuco (2017). De acuerdo con nuestros resultados, este alófono claramente ocurre en postmargen silábico, pero también se observa al inicio de sílaba, ratificando lo señalado por el estudio anterior.

Si bien [f] ocurre en la zona pewenche de Alto Bío-Bío; muestra una frecuencia significativamente menor que [v]. En cambio, en otros territorios es altamente frecuente, por lo que es descrito como la forma básica del fonema /f/; como es el caso del mapuche central (Echeverría 1964; Salas 1976; Salas 1978; Lagos 1981; Salamanca et. al, 2009; Sánchez y Salamanca, 2014; Pérez y Salamanca, 2016). De todos modos, este estudio confirma su presencia en el habla infantil de la zona.

El alófono fricativo bilabial sonoro [ $\beta]$, registró un total de 15 realizaciones $(3 \%)$ en las comunidades de ambos valles. Según las descripciones del habla de los adultos, presenta una baja ocurrencia en la zona (Sánchez, 1989, Salamanca, 1997). En efecto, Salamanca (1997) plantea que "ocurre solo en el premargen, en alternancia libre con [v] y con una frecuencia menor que el alófono labiodental" (p. 119). Investigaciones actuales constatan este alófono en el territorio y lo consideran como un indicador de vitalidad del fonema $/ \mathrm{v} /$ (Mena, 2016; Mena y Salamanca, 2018).

En relación con las variantes emergentes, el alófono oclusivo bilabial sonoro [b] y el alófono oclusivo bilabial áfono [p] son interpretados como realizaciones producto del contacto lingüístico. El alófono [b] se presenta tanto en el valle del Bío-Bío como en el valle del Queuco; pero no en la comunidad de Butalelbun.

Como sabemos, el alófono [b] no pertenece del sistema fonético-fonológico del mapudungun; pero sí forma parte del inventario de fonemas del español de Chile; sistema en el que alófono fricativo labiodental sonoro $[\mathrm{v}]$ es descrito como alófono de /b/ (Sadowsky y Salamanca, 2011). En este contexto, la realización de [b] como alófono de /v/ en el mapudungun, evidencia posible influencia del español, producto del contacto lingüístico, lo que es coherente con lo descrito por Mena y Salamanca (2018).

Por su parte, el alófono [p], registró 32 realizaciones (7\%). Está presente en las tres comunidades del valle del Queuco y solo en la comunidad de Ralco Lepoy del valle del Bío-Bío. Este fono no ha sido descrito como alófono del fonema $/ \mathrm{v} /$ en el inventario fonético-fonológico del pewenche hablado en Alto Bío-Bío. No obstante, sí ha sido 
reportado en hablantes adultos del mapuche - lafkenche de la comuna de Tirúa, donde se registra como variante de /v/ (Salamanca y Quintrileo, 2009). En la zona de Alto Bío-Bío, en hablantes adultos, fue registrado e interpretado como trasferencia desde el español (Mena y Salamanca, 2018). El siguiente gráfico (Figura 10), compara las realizaciones del segmento entre ambos valles:

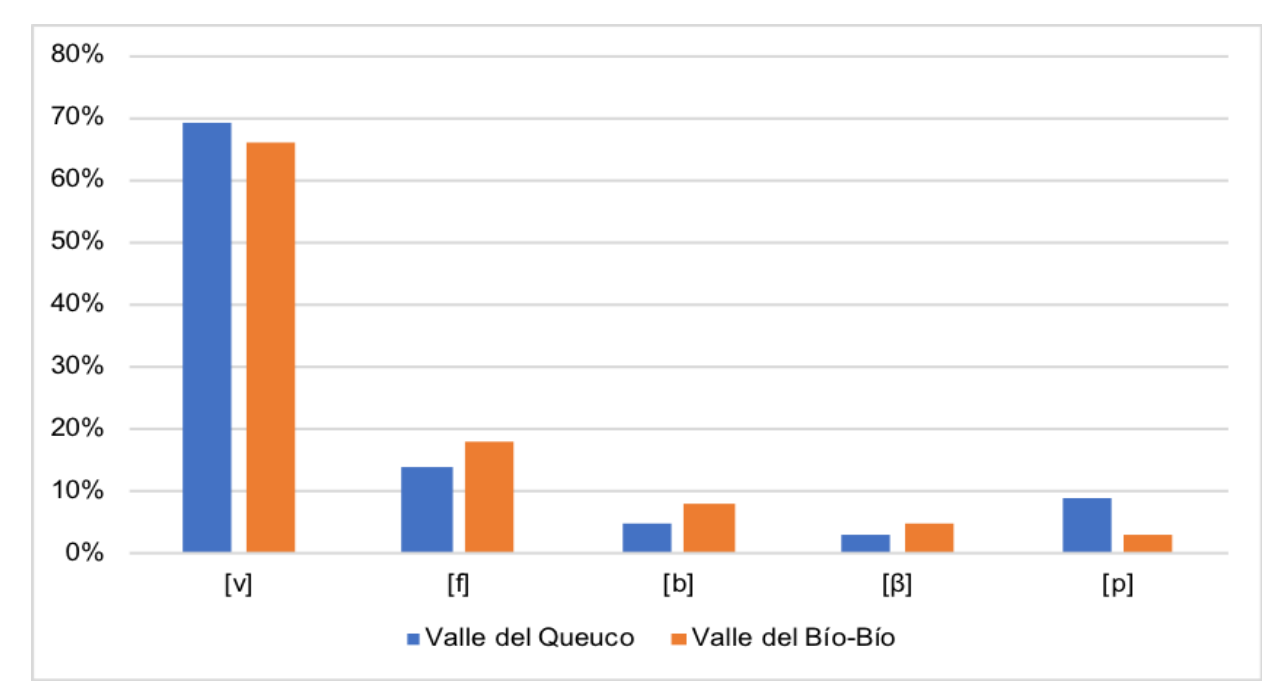

Figura 10. Comparación de realizaciones del segmento /v/ entre los valles del Queuco y Bío-Bío

\section{Reflexiones finales}

Dentro de los hallazgos del presente trabajo, se destaca en primer lugar la presencia de los 2 fonemas en estudio en el habla de los niños pewenches. Las variantes tradicionales de /ð/ y / $/$ descritas para los adultos de la zona, también se registran en el sistema fonológico de los niños, con un claro predominio. Así, la variante [ð] alcanza un 94\% y [v] un $68 \%$. De igual manera es relevante destacar la presencia en este grupo poblacional de realizaciones tradicionales que no son características del dialecto pewenche, sino del mapuche central hablado por adultos, como es el caso de $[\theta]$.

El análisis del corpus muestra que existe evidencia que permite hipotetizar variación por contacto, al comparar los resultados obtenidos con aquello que se ha descrito para el habla de los adultos, tanto del mapuche central como del mapuche pewenche del Alto BíoBío. En este ámbito destacamos: 
Artículo. Fernanda Narváez Fuentes, Marisol Henríquez Barahona. "Variación fonético-fonológica del mapudungun hablado por niños bilingües del Alto Bío-Bío: el caso de los fonemas fricativos $/ \mathrm{d} / \mathrm{y} / \mathrm{v} /$ "

a) El fonema / // presenta un alófono oclusivo postdental sonoro [d] en todas las comunidades estudiadas. Su presencia se interpreta como un rasgo de variación fonética-fonológica producto del contacto y de la influencia del castellano.

b) El fonema $/ \mathrm{v} /$ presenta una realización oclusiva bilabial sonora $[\mathrm{b}]$ y otra oclusiva bilabial áfona [p]; ambas son interpretadas igualmente como realizaciones motivadas por influjo del castellano, lo que coincide con lo descrito por Mena y Salamanca (2018).

Los resultados evidencian diferencias fonéticas-fonológicas en la realización de los fonemas /ð/ y /v/ según la procedencia geográfica de los niños. A nivel de macro-zona, los colaboradores que presentan mayor número y porcentaje de variantes tradicionales pertenecen a la comunidad de Butalelbun, mientras que los niños de la comunidad de El Barco son los que presentan menor número y porcentaje de variantes tradicionales. Este dato es relevante, pues la vitalidad fonológica asociada a ciertos territorios podría entregar información sobre la vitalidad de la lengua en la zona.

En cuanto a las variantes emergentes, se puede destacar lo siguiente:

a) La variante [d] se registró en ambos valles, sin embargo, presentó mayor frecuencia en la comunidad de El Barco (31\%), en cambio en la comunidad de Trapa Trapa fue donde tuvo menor presencia (3\%).

b) La variante [b], en el Queuco presentó mayor ocurrencia en la comunidad de Pitril (15\%) y en el valle del Bío-Bío en la comunidad de El Barco (11\%). Se destaca que la comunidad de Butalelbun no registró esta variante.

c) La variante [p] se registró en las tres comunidades del Queuco con porcentajes similares: Pitril (10\%), Trapa Trapa (9\%) y Butalelbun (8\%). En el valle del Bío-Bío, esta variante alcanzó un 4\% en Ralco Lepoy, mientras que en la comunidad de El Barco no se registró.

Finalmente es relevante destacar que los hallazgos presentados en este artículo aportan al diagnóstico y análisis fonético-fonológico del mapudungun en contacto $\mathrm{y}$ 
complementan las descripciones del habla infantil en el Alto Bío-Bío, considerando, además, que los abordajes previos, desarrollados en el habla infantil, se han centrado principalmente en comunidades del valle del Queuco y no del valle del Bío- Bío.

\section{FINANCIAMIENTO}

Los resultados de este estudio están asociados al proyecto Fondecyt de Iniciación $\mathrm{N}^{\mathrm{o}}$ 11150508 y la tesis para optar al grado de Magíster en Lingüística Aplicada de la autora principal.

\section{REFERENCIAS}

Alonqueo, Paula; Witig, Fernando y Huenchunao, Nataly. "LLeupeko Tuwün. Un estudio exploratorio sobre niveles de competencia en mapuzungun en niños mapuches de la Araucanía”. Revista Alpha 44 (2017): 119-135.

Areiza, Rafael; Cisneros, Mireya y Tabares, Luis. Hacia una nueva visión sociolingüistica. Bogotá: ECOE Ediciones, (2011).

Blas Arroyo, José. Sociolingüística del español. Desarrollos y perspectivas en el estudio de la lengua española en contexto social. Madrid: Cátedra, (2012).

Boersma, Paul y Weenink, David. Praat: doing phonetics by computer [Computer program]. Versión 6.0.50, (2019).

Correa, José. Manual de Análisis Acústico del Habla con PRAAT. Bogotá: Instituto Caro y Cuervo, (2014).

Croese, Robert. "Estudio dialectológico del mapuche”. Estudios Filológicos, 15(1980): 738.

Echeverría, Max. "Descripción fonológica del mapuche actual". Boletín del Instituto de Filología de la Universidad de Chile, XVI, (1964):13-59.

Escobar, Ana María y Wölck, Wolfang (Eds.) Contacto lingüístico y la emergencia de variantes y variedades lingüísticas. Vervuert: Iberoamericana, (2009).

Fuentes, Darío y Salamanca, Gastón. “¿Los fonemas /v/ y /ð/ presentan alófonos aproximantes en el chedungun hablado En El alto bío-bío? Evidencias desde una perspectiva acústica". Revista de Literatura y Lingüística, 33(2015): 267-288.

Henríquez Marisol. "Aproximaciones a la fonología del chedungun: un estudio exploratorio en niños pewenches del Alto Bío-Bío". Nueva Revista del Pacífico, 66 (2017), 99114.

Henríquez, Marisol y Gastón, Salamanca. "Vitalidad de la fonología segmental del chedungun hablado por escolares del Alto Bío-Bío". Alpha, 41 (2015): 207-231.

Lagos, Daniel. "El estrato fónico del mapudungu(n)". Nueva Revista del Pacífico 19-20 (1981): 42-66.

Mena, Daniela. Transferencias del español y estatus fonético-fonológico de $\left[\int\right]$ en el chedungun hablado en Alto Biobío. Tesis de Magíster en Lingüística Aplicada. Universidad de Concepción. (2016). 
Artículo. Fernanda Narváez Fuentes, Marisol Henríquez Barahona. "Variación fonético-fonológica del mapudungun hablado por niños bilingües del Alto Bío-Bío: el caso de los fonemas fricativos $/ \mathrm{d} / \mathrm{y} / \mathrm{v} /{ }^{\prime}$

Mena, Daniela y Salamanca Gastón. "Transferencias fonético-fonológicas del español en el mapudungun hablado por la población adulta de Alto Biobío, Octava Región, Chile". Revista de Literatura y Lingüística, 37 (2018): 237-251.

Moreno Fernández, Francisco. Principios de sociolingüística y sociología del lenguaje. Barcelona: Ariel, (2009).

Moreno, Alberto. Diccionario Mapuche. Argentina: Artemisa, (2014).

Palacios, Azucena. "Nuevas perspectivas en el estudio del cambio inducido por contacto hacia modelo dinámico del contacto de lenguas". Revista Lenguas Modernas, 38 (2011): 17-36.

Pérez, Chery y Salamanca, Gastón. "El mapuche hablado en Curarrehue: Fonemas segmentales, fonotaxis y comparación con otras variedades". Revista de Literatura y Lingüística, 35 (2016): 315-336.

Sadowsky, Scott y Salamanca, Gastón. "El inventario fonético del español de Chile: principios orientadores, inventario provisorio de consonantes y sistema de representación (AFI-CL)". Revista Onomázein 24 (2011): 61-84.

Sadowsky, Scott; Héctor, Painequeo; Gastón Salamanca y Heriberto, Avelino. "Mapudungun". Journal of the International Phonetic Association, 43(2013): 87-96.

Salamanca, Gastón. "Fonemas segmentales del pewenche hablado en el Alto Bío- Bío". RLA, 35(1997):113-124.

Salamanca, Gastón y Elizabeth Quintrileo. "Fonemas segmentales y muestra lexical del mapudungun hablado en Tirúa”. RLA, 47 (2009):13-35.

Salamanca, Gastón; Cifuentes, Edgardo y Figueroa, Mauricio. "Sistematización de criterios para la determinación de fonos, alófonos y formas básicas de los fonemas del español de Chile: una herramienta para la investigación y la docencia". Boletín de Filología, XLVI (2) (2011): 107-133.

Salas, Adalberto. "Esbozo fonológico del mapudungu, lengua de los mapuches o araucanos de Chile central". Estudios Filológicos, 11(1976):143-153.

."Mapuche-Español. Análisis fonológico contrastivo". VICUS. Cuadernos Lingüística, 2(1978):57-85.

Sánchez, Gilberto. "Relatos orales en pewenche chileno". Anales de la Universidad de Chile, 17 (1989):289-360.

Sánchez, Makarena y Salamanca. Gastón. "El mapuche hablado en Lonquimay: fonemas segmentales, fonotaxis y comparación con otras variedades". Revista de Literatura y Lingüística, 31(2014): 295-332.

Serrano, María José. Sociolingüística. Barcelona: Ediciones Serbal, (2011).

Silva-Corvalán, Carmen. Sociolingüistica y pragmática del español. Washington, DC.: Georgetown University Press, (2001).

Silva-Corvalán, Carmen y Arias, Andrés Enrique. Sociolingüística y pragmática del español. Washington: Georgetown University Press, (2017).

Thomason, Sarah. Language contact. Edinburgh: University Press, (2001).

Thomason, Sarah y Terrence, Kaufman. Language contact, creolization, and genetic linguistics. Bekerley/Los Angeles: University of California Press, (1988).

Wittig, Fernando y Alonqueo, Paula. "El mapuzungun en niños mapuche de La Araucanía. Reflexiones sobre adquisición de la lengua a partir de un estudio de medición directa”. Revista de Literatura y Lingüística, 38 (2018): 213-230. 